10

\title{
Влияние материала металлического подслоя и геометрии осаждения на формирование текстуры в пьезоактивных пленках ZnO
}

\author{
(C) А.Г. Веселов, ${ }^{1}$ В.И. Елманов, ${ }^{1}$ О.А. Кирясова, ${ }^{1}$ Ю.В. Никулин ${ }^{1,2}$ \\ ${ }^{1}$ Саратовский фрилиал института радиотехники и электроники им. В.А. Котельникова РАН, \\ 410019 Саратов, Россия \\ ${ }^{2}$ Саратовский национальный исследовательский государственный университет им. Н.Г. Чернышевского, \\ 410012 Саратов, Россия \\ e-mail: labsftwo@mail.ru
}

(Поступило в Редакцию 19 мая 2017 г.)

Исследовано влияние материала металлического подслоя (алюминий, ванадий, хром, железо, кобальт, никель, медь) и геометрии осаждения на формирование наклонной и прямой текстуры в пленках $\mathrm{ZnO}$, синтезируемых в магнетронной распылительной системе на постоянном токе. Установлено, что пьезоактивные пленки $\mathrm{ZnO}$ с наклонной текстурой, способные возбуждать сдвиговые волны, формируются на металлических подслоях $\mathrm{Cr}$ и $\mathrm{V}$ в сдвиговой геометрии осаждения (подложка смещена относительно оси магнетрона в область эрозии мишени). Пьезоактивные пленки ZnO с прямой текстурой, способные возбуждать продольные волны, сформированы в симметричной геометрии осаждения (подложка расположена по центру мишени) на химически чистом Al подслое. Изменение материала подслоя для каждой из геометрий осаждения или предварительное окисление подслоя привело к формированию пьезоактивных пленок ZnO со смешанной текстурой, возбуждающих сетку сдвиговых и продольных волн. С использованием метода химического травления показано, что получаемые пленки $\mathrm{ZnO}$ с наклонной текстурой проявляют пьезоактивные свойства и способны возбуждать гиперзвук начиная с толщины $\sim 0.3 \mu \mathrm{m}$, а пленки $\mathrm{ZnO}$ с прямой текстурой с толщины $\sim 0.9 \mu \mathrm{m}$.

DOI: 10.21883/JTF.2018.01.45490.2341

\section{Введение}

Пьезоактивные пленки $\mathrm{ZnO}$ с наклонной и прямой текстурой широко применяются при создании акустоэлектронных СВЧ устройств обработки сигналов резонаторов, фильтров, линий задержки, конвольверов [1-7]. Многообразие функций, выполняемых акустоэлектронными устройствами (калибровка расстояния, частотная селекция аналоговых сигналов, параллельный спектральный анализ), а также их устойчивость к вибрациям, электромагнитному излучению, температуре, бездисперсность являются причиной неослабевающего интереса к разработке и оптимизации технологий синтеза пьезоактивных текстурированных пленок $\mathrm{ZnO}$, а также создания однослойных и многослойных [8] структур на их основе.

На сегодняшний день для формирования пьезоактивных пленок $\mathrm{ZnO}$ с прямой или наклонной текстурой и создания пьезоакустических преобразователей широко применяются методы магнетронного распыления (высокочастотного [2,3,7,9-12] и на постоянном токе $[8,13-15])$, а также реактивное [16]) ионно-лучевое [17] и лазерное [18] распыления. При этом большинство работ по методам получения текстурированных пленок $\mathrm{ZnO}$ посвящено исследованию условий синтеза пленок с прямой текстурой $-\mathrm{ZnO}(002)$. В значительной степени это связано с тем, что кристаллическая фаза $\mathrm{ZnO}(002)$ обладает наименьшей поверхностной энергией, поэтому легко формируется как на ориентирующей, так и на аморфной подложке. Кроме того, синтез пленок оксида цинка с наклонной (лежащей) текстурой является существенно более трудной технической задачей, связанной со сложностью реализации ориентирующих факторов, определяющих наклон оси текстуры.

Для методов высокочастотного, ионно-лучевого и реактивного распылений было показано, что положение подложки относительно центра мишени и давление рабочего газа существенным образом влияют на формирование текстуры в пленках $\mathrm{ZnO}$ в отличие от материала металлического подслоя $[11,12]$. Так, при создании пленок $\mathrm{ZnO}$ с прямой текстурой и пьезопреобразователей на их основе используются симметричная геометрия осаждения (подложка расположена по центру мишени) и высокое ( $P>5 \mathrm{mT}$ Torr) давление рабочего газа. Для формирования нижнего металлического электрода, как правило, применяются металлы (Al, $\mathrm{Cu}$, $\mathrm{Au}, \mathrm{Pt})$ с ГЦК кристаллической структурой, склонные формировать текстуру (111), оказывающую ориентирующее влияние на формирование прямой текстуры $\mathrm{ZnO}(002)[3,5,10,12,19,20]$. Для синтеза пленок $\mathrm{ZnO}$ с наклонной или лежащей текстурой (10.0) или (11.0) осаждение происходит при низком давлении рабочего газа $(P<5$ mTorr $)$, подложка размещается параллельно мишени в зоне эрозии (сдвиговая геометрия) $[21,16]$ или под наклоном к мишени $[11,12,17]$, а в качестве материала металлического подслоя могут использоваться металлы $\mathrm{Al}, \mathrm{Cu}, \mathrm{Zn}[11,12,17]$. Отметим, что наклонная геометрия осаждения пленок $\mathrm{ZnO}$ может приводить 
к неоднородности по толщине и углу наклона кристаллитов. Неоднородность толщины в свою очередь обеспечивает искажение фронта распространения возбужденной в кристалле акустической волны. Поэтому для формирования пьезоакустических преобразователей на сдвиговых волнах (особенно многослойных [8]) наклонная геометрия не может рассматриваться в качестве эффективного технологического решения.

Метод магнетронного распыления на постоянном токе (МРПТ) также позволяет синтезировать в сдвиговой и симметричной геометриях осаждения пьезоактивные текстурированные пленки $\mathrm{ZnO}[8,13,15,22]$, способные возбуждать гиперзвук в диапазоне частот до $18 \mathrm{GHz}[14]$. При этом реализация в одном технологическом процессе различных геометрий осаждения [8] дает возможность совмещения слоев $\mathrm{ZnO}$ с прямой и наклонной текстурой и создания многослойных структур на их основе. На примере двухслойной структуры на основе пленок $\mathrm{ZnO}$ с наклонной и прямой текстурой в [8] было показано, что пленки $\mathrm{ZnO}$ с наклонной текстурой вносят меньшие акустические потери при распространении как сдвиговых, так и продольных волн по сравнению с пленками $\mathrm{ZnO}$ с прямой текстурой.

Однако для пленок $\mathrm{ZnO}$, синтезируемых методом МРПТ, влияние материала металлического подслоя и его чистоты на формирование наклонной и прямой текстуры для разных геометрий осаждения не обсуждалось.

В настоящей работе для пленок $\mathrm{ZnO}$, осаждаемых методом МРПТ, показано, что выбор материала металлического подслоя и его чистота, так же как геометрия осаждения, оказывают решающее влияние на формирование наклонной и прямой текстуры. Установлено, что воспроизводимый и стабильный синтез пьезоактивных пленок $\mathrm{ZnO}$ с наклонной текстурой толщиной $d<1 \mu \mathrm{m}$ возможен только в сдвиговой геометрии на металлических подслоях из хрома $(\mathrm{Cr})$ или ванадия $(\mathrm{V})$. Пьезоактивные пленки $\mathrm{ZnO}$ с прямой текстурой формируются только в прямой геометрии осаждения на химически чистом алюминиевом (Al) подслое. Изменение материала подслоя для каждой из геометрий осаждения или предварительное окисление подслоя приводит к формированию пьезоактивных поликристаллических пленок (без выделенной кристаллографической ориентации - текстуры). С применением метода химического травления в водном растворе $\mathrm{HCl}(0.012 \mathrm{M})$ определена толщина $d$, при которой происходит потеря пьезоактивности в пленках $\mathrm{ZnO}$ с наклонной и прямой текстурой.

\section{1. Эксперимент}

Синтез текстурированных пленок $\mathrm{ZnO}$ с наклонной $(d \approx 0.88 \mu \mathrm{m})$ и прямой $(d \approx 1.9 \mu \mathrm{m})$ текстурой производился в планарной несбалансированной магнетронной распылительной системе с базовым давлением $P_{b} \approx 0.01$ mTorr с квазизамкнутым объемом зоны горения плазмы (рис. 1). Квазизамкнутый объ- ем представлял собой кварцевый стакан диаметром $D \approx 40 \mathrm{~mm}$, нижняя часть которого ограничивалась магнитной системой магнетрона (катод), а верхняя пластиной из алюминия (анод, находящийся под потенциалом „земли“) с двумя отверстиями в центре и на расстоянии $15 \mathrm{~mm}$ от центра (область эрозии мишени). Использование квазизамкнутого объема позволяло стабилизировать по давлению условия синтеза пленок ZnO. В качестве рабочего газа использовалась смесь газов - 70\% кислорода (чистота 99.999\%) и $30 \%$ аргона (чистота 99.999\%). В качестве мишени использовалась фольга $\mathrm{Zn}$ (диаметр $\approx 40 \mathrm{~mm}$, толщина $\approx 1 \mathrm{~mm}$, чистота 99.99\%). Осаждение пленок $\mathrm{ZnO}$ производилось при давлении рабочего газа внутри квазизамкнутого объема $P \approx 0.75-0.77$ mTorr (давление за пределами квазизамкнутого объема $P \approx 0.24-0.26$ mTorr), токе разряда $I \approx 100-120 \mathrm{~mA}$, напряжении на магнетроне $U \approx-550 \mathrm{~V}$ и температуре подложки $T_{s} \approx 300^{\circ} \mathrm{C}$. В качестве подложки-звукопровода использовался монокристаллический алюмоиттриевый гранат, легированный лютецием (АИГ) с площадью поверхности под осаждение пленки $5 \times 5 \mathrm{~mm}^{2}$.

Возбуждение и регистрация акустических колебаний в пьезопреобразователях на основе текстурированных пленок $\mathrm{ZnO}$ производились на измерительной установке, состоящей из импульсного СВЧ генератора $(845 \mathrm{MHz}$, длительность импульса $1 \mu \mathrm{s})$, усилителя и осциллографа. Мощность СВЧ электромагнитного поля, подводимого непосредственно к пьезоактивному преобразователю (рис. 2) через коаксиальный проводник с центральным электродом диаметром $100 \mu \mathrm{m}$ составляла $0.1-0.5 \mathrm{~W}$. В эксперименте измерялись общие потери звука (по величине первого эхо-импульса) для структур, представленных на рис. 2. Отметим, что, поскольку $\mathrm{ZnO}$ является полярным кристаллом, с точки зрения эффективности возбуждения звука текстурированными пленками $\mathrm{ZnO}$ решающее значение имеет однополярность кристаллитов по всей пленке. Прямым способом оценки однородности текстуры пленки и эффективности возбуждения гиперзвука является наблюдение на осциллограммах однородной по амплитуде сетки продольных или сдвиговых волн, возбуждаемых СВЧ зондом малого диаметра $(100 \mu \mathrm{m})$ на различных участках пленок с прямой или наклонной текстурой.

Для создании пьезопреобразователей на основе пленок $\mathrm{ZnO}$ в качестве материала подслоя использовались металлы (Al, V, Cr, Fe, Co, Ni, Cu) чистотой 99.99\%. Металлический подслой толщиной $d \approx 100 \mathrm{~nm}$ осаждался на подложку АИГ при температуре $T_{s} \approx 150(\mathrm{~V})$ и $\approx 300^{\circ} \mathrm{C}(\mathrm{Al}, \mathrm{Cr}, \mathrm{Fe}, \mathrm{Co}, \mathrm{Ni}, \mathrm{Cu})$ термическим осаждением из танталового тигля при давлении остаточной атмосферы $P_{b} \approx 0.01-0.03$ mTorr. Размеры тигля, навеска материала, скорость нагрева тигля подбирались таким образом, чтобы скорость напыления составляла около $100 \mathrm{~nm} / \mathrm{s}$. Это позволяло за время осаждения около $1 \mathrm{~s}$ получать металлические пленки с малым содержанием примесей и высокой электропроводностью. 

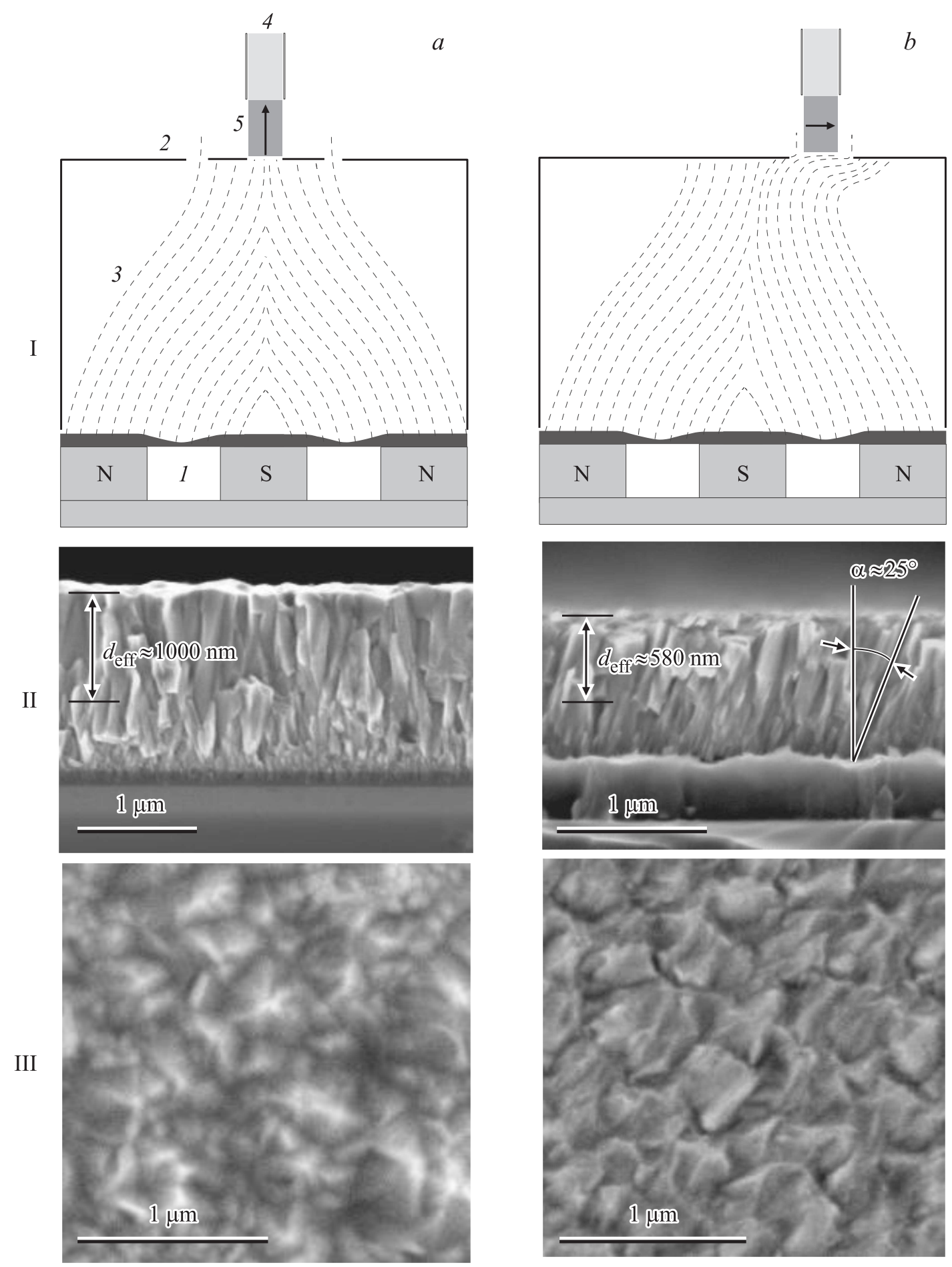

Рис. 1. I - схема расположения подложки-звукопровода для формирования пленок ZnO с прямой (a) и наклонной текстурами $(b): 1$ - магнитная система магнетрона с мишенью $\mathrm{Zn}, 2$ - квазизамкнутый объем с анодом из алюминия и отверстиями для размещения подложки, 3 - зона горения плазмы (штриховыми линиями схематически показана светящаяся область рекомбинационного горения), 4 - подложка АИГ с нагревателем, 5 - пленка $\mathrm{ZnO}$ (стрелкой показано направление оси текстуры пленки, формирующейся в данной геометрии осаждения); II, III - CЭМ изображения поперечного сечения (II) и поверхности (III) пленок $\mathrm{ZnO}$ с прямой $(a)$ и наклонной $(b)$ текстурами. Величина $d_{\mathrm{eff}}$ обозначает часть пленки, обладающую пьезоактивными свойствами.

После нанесения металлического подслоя подложка без развакууммирования в течение $3-5 \mathrm{~s}$ переносилась в область плазмохимического реактора и размещалась на расстоянии $L \approx 20 \mathrm{~mm}$, обеспечивающим стехиометричность состава $\mathrm{ZnO}$ [14]. После этого зажигалась реакционная плазма и происходило осаждение пленок 


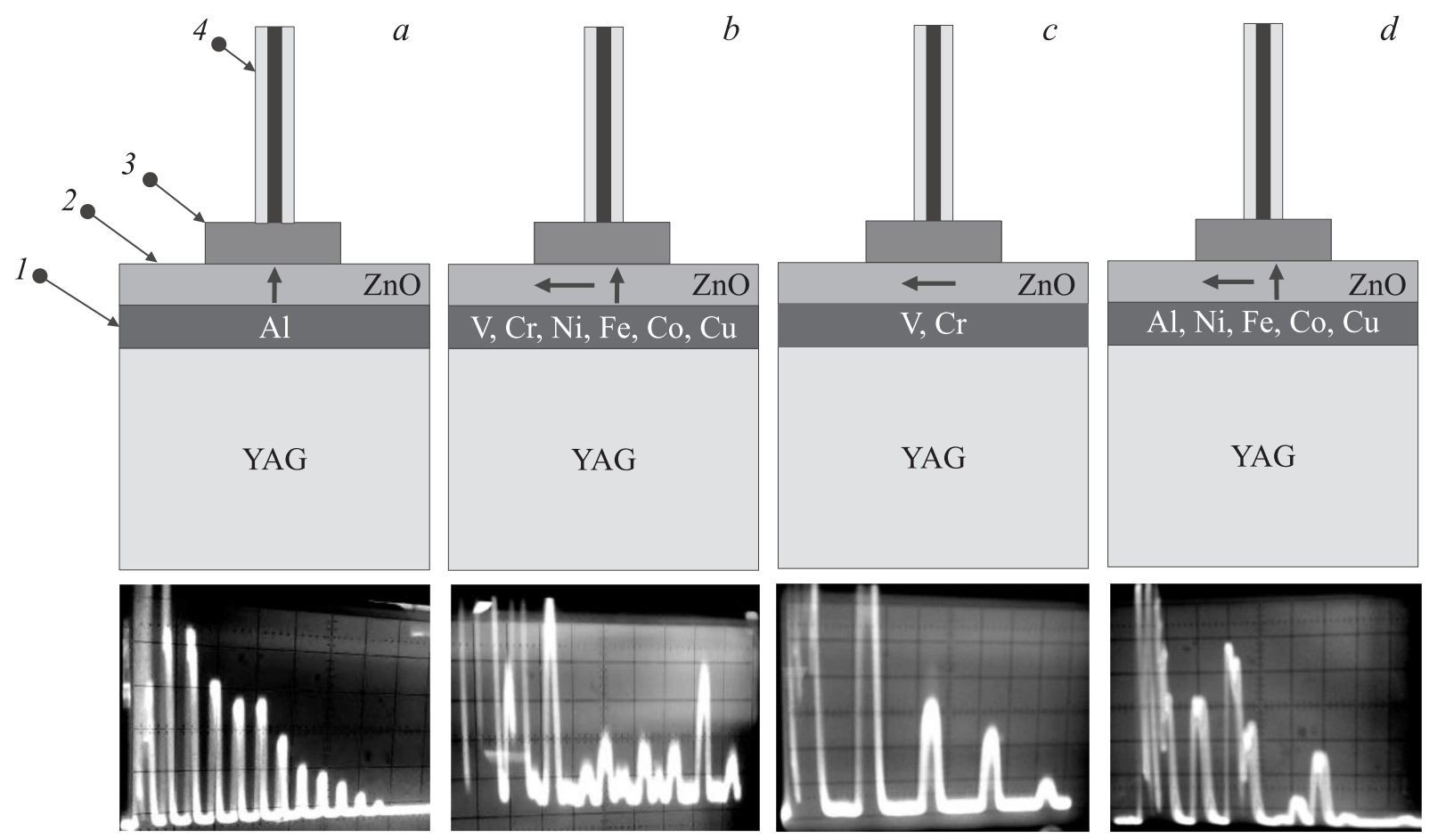

Рис. 2. Схематические изображения пьезоакустических преобразователей на основе текстурированных пленок $\mathrm{ZnO}$ (прямая (a) и наклонная (c) текстуры), а также поликристаллических пленок $\mathrm{ZnO}(b, d)$, формируемых на различных металлических подслоях на подложке АИГ, расположенной по центру мишени $(a, b)$ и в зоне эрозии мишени $(c, d): 1,3-$ металлические электроды, $2-$ текстурированная или поликристаллическая пьезоактивная пленка $\mathrm{ZnO}, 4-\mathrm{CBЧ}$ зонд диаметром $100 \mu \mathrm{m}$. Под изображениями пьезопреобразователей приведены осциллограммы $(1 \mu \mathrm{s} / \mathrm{cm})$ продольных $(a)$ и сдвиговых $(c)$, а также смешанных $(b, d)$ типов волн, возбуждаемых соответствующими пьезопреобразователями.

$\mathrm{ZnO}$. За указанное время переноса и поджига плазмы металлическая пленка не успевала окислиться в остаточной атмосфере вакуумной камеры, что обеспечивало возможность осаждения $\mathrm{ZnO}$ на химически чистую поверхность металла. При выбранных ростовых условиях использование конструкции плазмохимического реактора, представленной на рис. 1, а также выбор материала металлического подслоя для каждой из геометрий осаждения позволяли синтезировать пьезоактивные пленки $\mathrm{ZnO}$ с наклонной и прямой текстурой при скоростях осаждения $v \approx 60 \mathrm{~nm} / \mathrm{min}$ с высокой стабильностью и воспроизводимостью.

\section{2. Обсуждение результатов}

\section{1. Прямая текстура}

В симметричной геометрии осаждения, показанной на рис. 1, $a$ подложка располагалась по центру магнетрона на расстоянии $L \approx 20 \mathrm{~mm}$ от мишени в области инверсии поперечной составляющей магнитного поля магнетрона (область кроссовера) [14]. Результаты исследования сколов пленок методом сканирующей электронной микроскопии (СЭМ) (Auriga, CarlZeiss) показали, что при выбранных условиях осаждения формируются пленки $\mathrm{ZnO}$ со столбчатой структурой по толщине со средним значением размера зерна в плоскости пленки около 200-800 nm (рис. $1, a \mathrm{II}, a \mathrm{III})$ и среднеквадратичной шероховатостью поверхности около $10 \mathrm{~nm}$.

Установлено, что если в качестве материала металлического подслоя в прямой геометрии используется Al (ГЦК кристаллическая решетка, высокое сродство к кислороду), то на нем формируются пленки $\mathrm{ZnO}$ с прямой текстурой. Создаваемые на их основе пьезоакустические преобразователи возбуждают продольные волны (рис. 2, 3) с величиной вносимых потерь около 47-53 dВ. Такая величина потерь обусловлена недостаточным согласованием подводящей СВЧ линии с пленкой $\mathrm{ZnO}$, а также различием акустических импедансов АИГ и ZnO. Отметим, что если после напыления подслоя алюминия подложка АИГ выносилась хотя бы на 1 min на атмосферу, то на окисленном Al подслое формировались поликристаллические (без текстуры) пленки $\mathrm{ZnO}$. При возбуждении звука, отсутствие текстуры проявлялось на осциллограммах в виде смешанной сетки продольных и сдвиговых волн (рис. $2, b$ ). Если в качестве материала подслоя использовались металлы $\mathrm{Cu}, \mathrm{Cr}, \mathrm{V}$, $\mathrm{Ni}, \mathrm{Co}, \mathrm{Fe}$, то на них также формировались пьезоактивные поликристаллические пленки $\mathrm{ZnO}$, возбуждающие смешанную сетку сдвиговых и продольных волн (рис. 2,a). Полученные результаты свидетельствуют о 


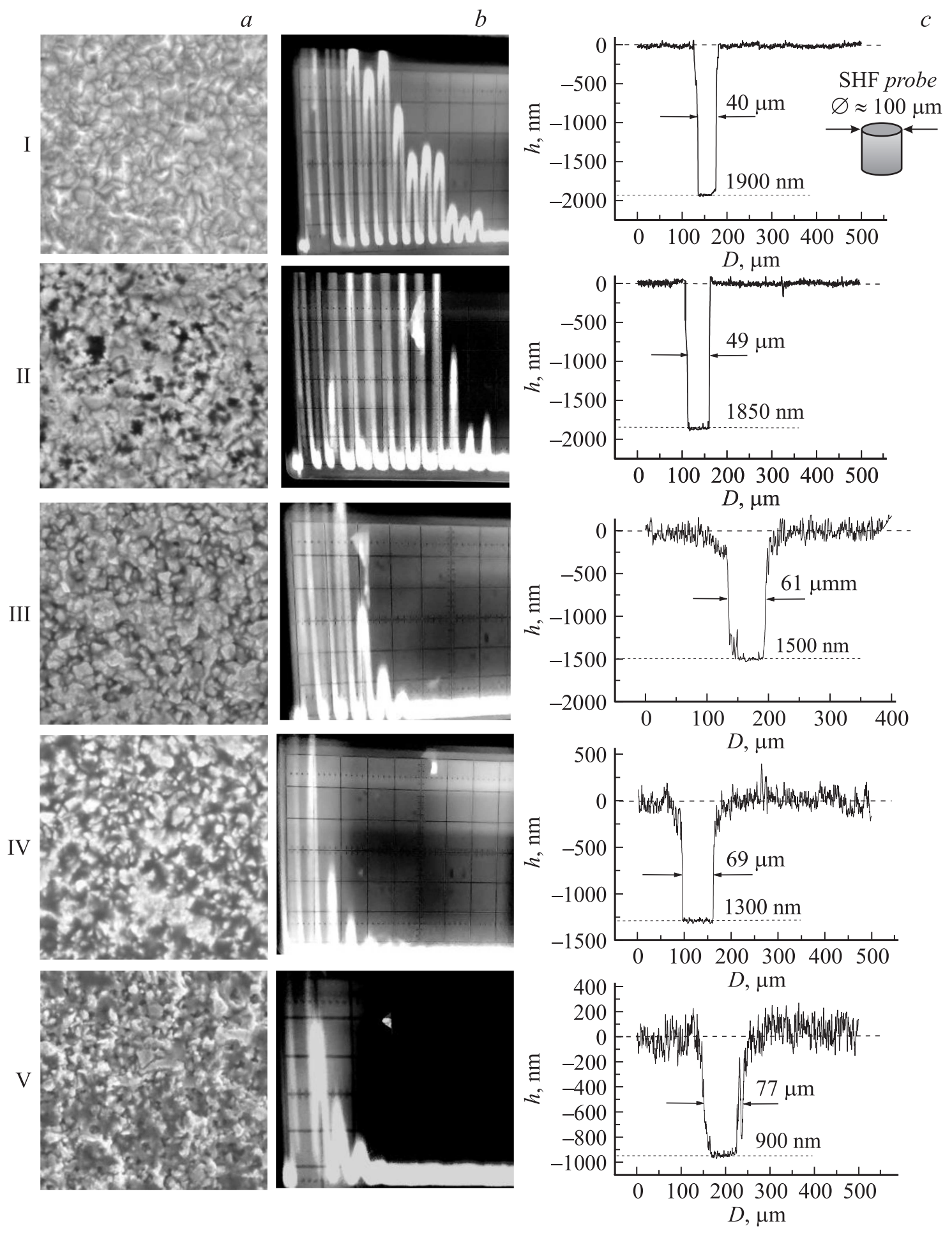

Рис. 3. $a-\mathrm{CЭM} \mathrm{изображения} \mathrm{поверхности}\left(4 \times 4 \mu \mathrm{m}^{2}\right)$, осциллограммы $(b)$ и профили $(c)$ пленок $\mathrm{ZnO}$ с прямой текстурой $(d \approx 1900 \mathrm{~nm})$ до и после травления в водном растворе $\mathrm{HCl}(0.012 \mathrm{M})$ в течение $t, \min : 1-0,2-\approx 1,3-\approx 7,4-\approx 9,5-$ $\approx 13$. Масштаб для осциллограмм $-1 \mu \mathrm{s} / \mathrm{cm}$.

том, что для метода МРПТ материал подслоя и его чистота являются одними из решающих факторов для формирования прямой текстуры в пленках $\mathrm{ZnO}$.

Для оценки толщины, при которой пленка $\mathrm{ZnO}$ с прямой текстурой теряет пьезоактивные свойства, была проведена серия экспериментов по травлению в водном растворе $\mathrm{HCl}(0.012 \mathrm{M}$ [23]) на основе деионизованной воды с удельным сопротивлением $0.06 \mu \mathrm{s} / \mathrm{cm}$ при комнатной температуре. До и после травления изучались морфология поверхности пленок (СЭМ), толщина $d$, 

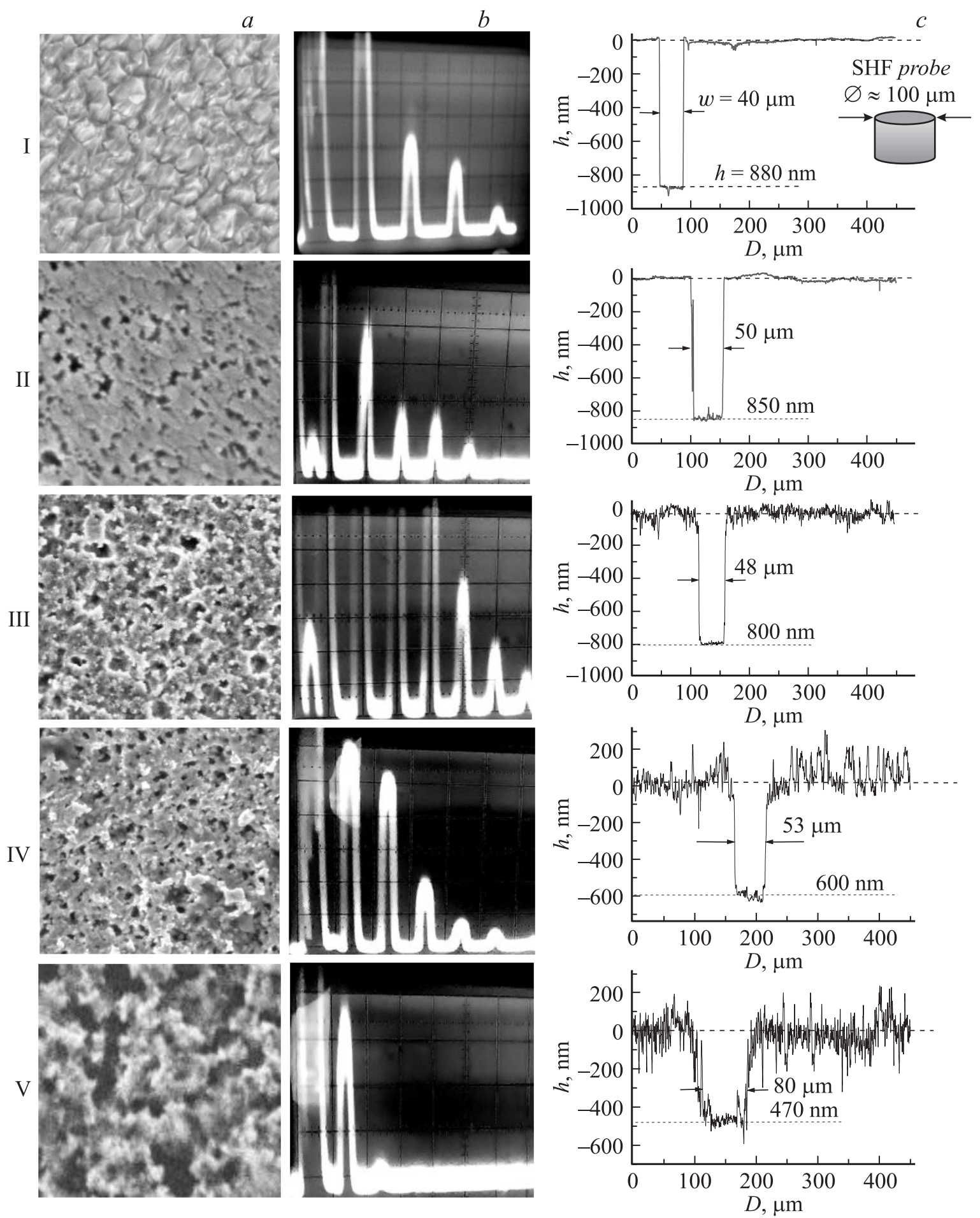

Рис. 4. $a-$ СЭМ изображения поверхности $\left(4 \times 4 \mu \mathrm{m}^{2}\right)$, осциллограммы $(b)$ и профили $(c)$ пленок $\mathrm{ZnO}$ с наклонной текстурой $(d \approx 880 \mathrm{~nm})$ до и после травления в водном растворе $\mathrm{HCl}(0.012 \mathrm{M})$ в течение $t$, min: $1-0,2-\approx 1,3-\approx 2,4-\approx 3,5-\approx 4$. Масштаб для осциллограмм $-1 \mu \mathrm{s} / \mathrm{cm}$.

среднеквадратичная шероховатость поверхности $\sigma$ и пьезоакустические свойства (вносимые потери, число эхо-импульсов). Профиль пленки $\mathrm{ZnO}$ формировался методом скрайбирования (царапина шириной $40 \mu \mathrm{m}$ ). Оценка толщины $d$ и шероховатости поверхности $\sigma$ на площади $500 \times 500 \mu \mathrm{m}^{2}$ производилась методом профилометрии (Dectak 150, Veeco). В качестве критерия оценки толщины $d$, при которой пленка $\mathrm{ZnO}$ утрачивает пьезоактивные свойства, была выбрана величина вносимых потерь $90 \mathrm{~dB}$, определяемая по первому 

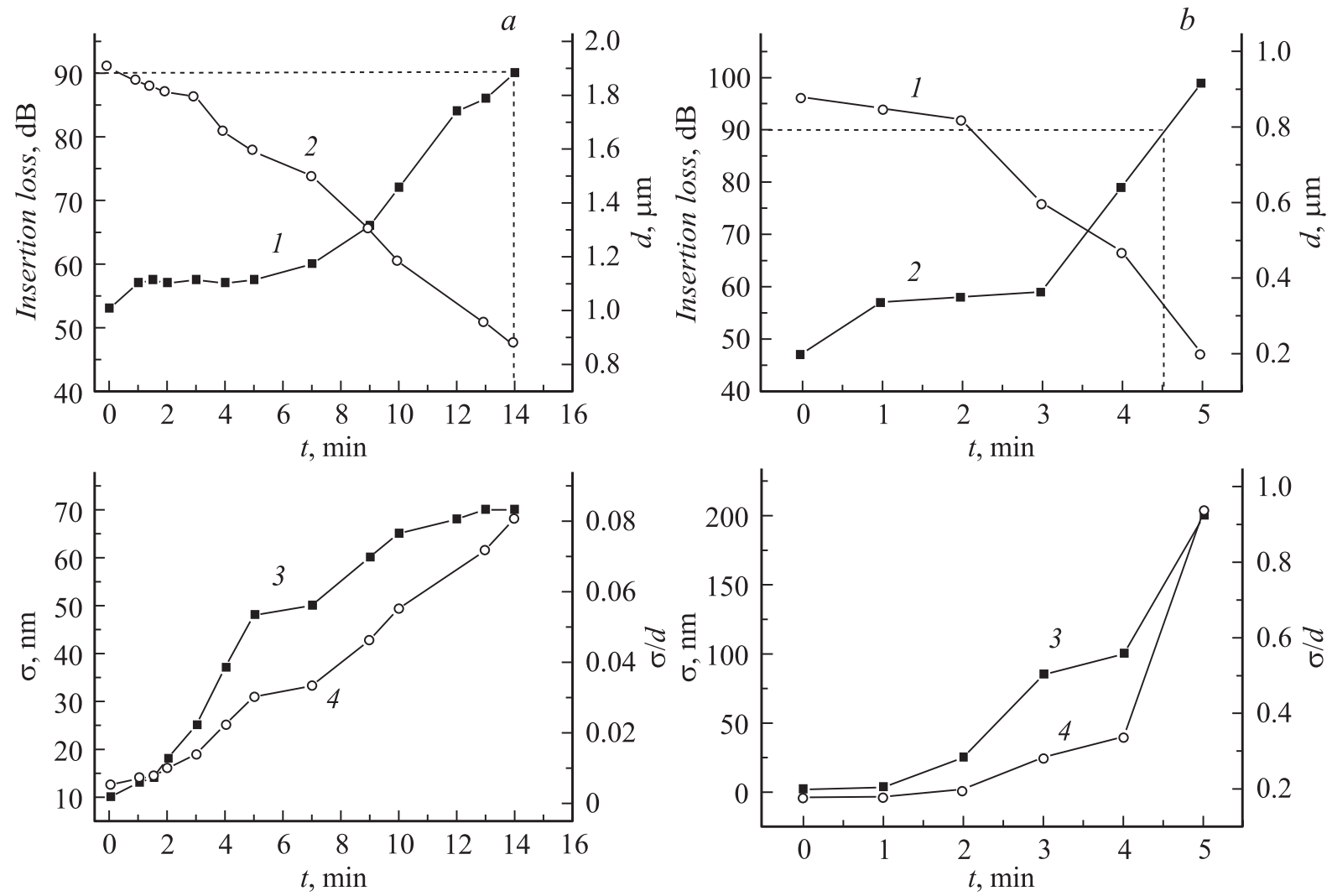

Рис. 5. Зависимости величины вносимых потерь (кривая 1), толщины пленки $d$ (кривая 2), шероховатости поверхности $\sigma$ (кривая 3) и приеденной шероховатости $\sigma / d$ (кривая 4) от времени травления $t$ для пленок $\mathrm{ZnO}$ с прямой $(a)$ и наклонной $(b)$ текстурами.

эхо-импульсу. При достижении этого значения считалось, что пленка $\mathrm{ZnO}$ перестала эффективно возбуждать звук.

На рис. 4 представлены типичные изображения участков поверхности $\left(\right.$ СЭМ, $\left.4 \times 4 \mu \mathrm{m}^{2}\right)$, осциллограммы и профили пленок $\mathrm{ZnO}$ с прямой текстурой до (рис. 4, $a$ ) и после травления (рис. 4,b). На рис. 5, $a$ приведены зависимости вносимых потерь, толщины $d$, шероховатости поверхности $\sigma$ и отношения $\sigma / d$ от времени травления $t$. Изображения поверхностей и профилей пленок $\mathrm{ZnO}$ показывают, что процесс травления характеризуется высокой равномерностью по площади образца (однородная по всей пленке текстура) и происходит преимущественно по границам зерен, о чем говорит значительное увеличение шероховатости поверхности с $10(t \approx 0)$ до $50-70 \mathrm{~nm}(t \approx 5-14 \mathrm{~min})$.

Из осциллограмм на рис. 4 и зависимости вносимых потерь от времени травления $t$ (рис. 5) видно, что пьезоакустические свойства пленок с прямой текстурой после травления в течение $1 \leq t \leq 6 \mathrm{~min}$ $(d \approx 1900-1550 \mathrm{~nm}, \sigma \approx 13-50 \mathrm{~nm}, \sigma / d \approx 0.007-0.03)$ ухудшаются незначительно - на осциллограммах наблюдается 12-20 эхо-импульсов, величина потерь составляет 53-58 dВ. Увеличение времени травления до $7 \leq t \leq 10 \mathrm{~min} \quad(1.4 \leq d \leq 1.15 \mu \mathrm{m}, \sigma \approx 50-65 \mathrm{~nm}$, $\sigma / d \approx 0.035-0.055)$ приводит к снижению числа наблюдаемых эхо-импульсов до 6-7 и росту вносимых потерь до 60-72 dВ. При $12 \leq t \leq 14 \min (1 \leq d \leq 0.9 \mu \mathrm{m}$, $\sigma \approx 70 \mathrm{~nm}, \sigma / d \approx 0.08)$ пленка все еще остается пьезоактивной - на осциллограммах наблюдаются первые три эхо-импульса, однако величина потерь составляет 84-90 dB. Ухудшение пьезоакустических свойств пленок $\mathrm{ZnO}$ при увеличении времени травления $t$ обусловлено уменьшением толщины $d_{\text {eff }}$ пьезоактивного слоя $\mathrm{ZnO}$ (достигается текстура зарождения, не обладающая пьезоактивными свойствами) и усилением вклада рассеяния звука на поверхностных неоднородностях.

Таким образом, пленки $\mathrm{ZnO}$ с прямой текстурой, осаждаемые на алюминиевый подслой, проявляют пьезоактивные свойства и способны возбуждать звук начиная с толщины $d \approx 0.9 \mu \mathrm{m}$.

\section{2. Наклонная текстура}

Для синтеза пленок $\mathrm{ZnO}$ с наклонной текстурой $(d \approx 0.88 \mu \mathrm{m})$ использовалась геометрия осаждения, показанная на рис. $1, b-$ сдвиговая геометрия. Подложка АИГ располагалась параллельно мишени при $L \approx 20 \mathrm{~mm}$ на расстоянии $R \approx 15 \mathrm{~mm}$ (область эрозии мишени) относительно оси магнетрона по центру отверстия в аноде 
квазизамкнутого объема. В такой геометрии осаждения атомы распыленного материала в области подложки имеют составляющую скорости, параллельную подложке, что способствует формированию наклонной текстуры в пленках $\mathrm{ZnO}$ (рис. 2,d). Микроструктура пленок $\mathrm{ZnO}$, формируемых в сдвиговой геометрии, является столбчатой с углом наклона кристаллитов относительно нормали к пленке около $25^{\circ}$, средним значением размера кристаллитов в плоскости пленки около 500-800 nm (рис. $1, a \mathrm{II}, a \mathrm{III}$ ) и средней шероховатостью поверхности около 2-3 nm (на площади $\left.100 \times 100 \mu \mathrm{m}^{2}\right)$.

Для сдвиговой геометрии осаждения установлено, что если нижний электрод изготавливается из металлов $\mathrm{Cr}$ и $\mathrm{V}$ (ОЦК кристаллическая решетка, малое сродство к кислороду), то на нем формируются пленки $\mathrm{ZnO}$ с наклонной текстурой, а пьезоакустические преобразователи на их основе эффективно возбуждают сдвиговые волны с величиной вносимых потерь около 47-53 dB (рис. $1, b)$. Если для создания металлического подслоя используются $\mathrm{Al}, \mathrm{Cu}, \mathrm{Ni}, \mathrm{Co}, \mathrm{Fe}$, то на них формируются пьезоактивные поликристаллические пленки $\mathrm{ZnO}$ - на осциллограммах наблюдается смешанная сетка продольных и сдвиговых волн (рис. 2).

Таким образом, полученные для двух геометрий осаждения результаты показывают, что для метода МРПТ выбор материала подслоя и его чистота являются наряду с давлением рабочего газа и температурой подложки $[8,22]$ определяющими технологическими факторами для формирования пьезоактивных пленок $\mathrm{ZnO}$ с наклонной и прямой текстурой.

Для оценки толщины, при которой пленка $\mathrm{ZnO}$ с наклонной текстурой теряет пьезоактивные свойства, была проведена серия экспериментов по травлению в водном растворе $\mathrm{HCl}(0.012 \mathrm{M})$. Структурные и пьезоакустические свойства оценивались аналогично пленкам $\mathrm{ZnO}$ с прямой текстурой.

На рис. 4 представлены типичные изображения участков поверхности, осциллограммы и профили пленок до (рис. 4, $a$ ) и после травления (рис. 4,b) в течение $t \approx 1-4 \mathrm{~min}$. Из изображений профилей пленок видно, что травление, так же как и для пленок с прямой текстурой, происходит равномерно по поверхности образца (однородная по всей площади образца наклонная текстура) преимущественно по границам зерен, о чем свидетельствует значительное увеличение шероховатости поверхности: для $t \approx 4 \mathrm{~min}$ величина $\sigma$ достигает $100 \mathrm{~nm}(\sigma / d \approx 0.2)$.

Исследование пьезоакустических свойств пленок $\mathrm{ZnO}$ с наклонной текстурой после травления в течение $t \approx 1-3 \mathrm{~min}(d \approx 850-600 \mathrm{~nm}, \sigma \approx 3.5-85 \mathrm{~nm}$, $\sigma / d \approx 0.004-0.1)$ показало, что пленки сохраняют пьезоактивность и эффективно возбуждают звук - на осциллограммах наблюдаются 5-10 эхо-импульсов, а величина потерь составляет 57-59 dВ. Увеличение времени травления до $t \approx 4 \min (d \approx 470 \mathrm{~nm}, \sigma \approx 100 \mathrm{~nm}$, $\sigma / d \approx 0.2)$ приводит к заметному ухудшению пьезоакустических свойств - пьезопреобразователи возбуждают сдвиговые волны с величиной потерь около $79 \mathrm{~dB}$, при этом наблюдаются два-три эхо-импульса. Травление в течение $5 \mathrm{~min}$ приводит почти к полному стравливанию пленки (величина вносимых потерь около $100 \mathrm{~dB}$, $\sigma \approx 200 \mathrm{~nm}, \quad \sigma / d \approx 1)$. Ухудшение пьезоакустических свойств пленок $\mathrm{ZnO}$ с наклонной текстурой после травления связано с уменьшением толщины пьезоактивного слоя $d_{\text {eff }}$ и значительным увеличением шероховатости поверхности пленки $(\sigma / d \approx 0.2)$, приводящего к усилению рассеяния звука на поверхностных неоднородностях.

Таким образом, полученные результаты показывают, что пленки $\mathrm{ZnO}$ с наклонной текстурой, осаждаемые на подслоях $\mathrm{Cr}$ или $\mathrm{V}$, проявляют пьезоактивные свойства и способны возбуждать звук начиная с толщины $d \approx 0.3 \mu \mathrm{m}$.

\section{Заключение}

На примере несбалансированной магнетронной распылительной системы на постоянном токе показано, что возникновение прямой и наклонной текстуры в пленках $\mathrm{ZnO}$ определяется не только расположением подложки относительно оси магнетронной системы, но также материалом подслоя и его чистотой. Для стабильного и воспроизводимого синтеза пьезоактивных пленок $\mathrm{ZnO}$ с наклонной текстурой и создания пьезоакустических преобразователей на сдвиговых волнах в качестве материала металлического подслоя следует использовать $\mathrm{Cr}$ или V, при этом подложка должна быть расположена над зоной эрозии мишени. Для создания пьезоакустических преобразователей на продольных волнах на основе пленок $\mathrm{ZnO}$ с прямой текстурой в качестве материала нижнего металлического электрода следует использовать Al, при этом подложка должна быть расположена по центру распыляемой мишени. Показано, что синтезируемые пленки $\mathrm{ZnO}$ проявляют пьезоактивные свойства и возбуждают гиперзвук начиная с толщин $d \approx 0.3 \mu \mathrm{m}$ (наклонная текстура) и $d \approx 0.9 \mu \mathrm{m}$ (прямая текстура).

Полученные в настоящей работе результаты могут представлять интерес для развития и оптимизации технологии синтеза методом МРПТ текстурированных пьезоактивных пленок $\mathrm{ZnO}$ толщиной менее $1 \mu \mathrm{m}$, перспективных при разработке акустоэлектронной элементной базы для создания защищенных от электромагнитного излучения СВЧ устройств обработки информации гигагерцового диапазона.

Работа выполнена при финансовой поддержке РФФИ: гранты № 16-29-14058, 16-37-60052,

\section{Список литературы}

[1] Алексеев С.Г., Гуляев Ю.В., Котелянский И.М., Мансфельд Г.Д. // УФН. 2005. Т. 175. № 8. С. 895-900.

[2] Corso C.D., Dickherber A., Hunt W.D. // J. Appl. Phys. 2007. Vol. 101. P. 054514-1-054514-7. 
[3] Yoshino Y. // J. Appl. Phys. 2009. Vol. 105. P. 061623-1061623-7.

[4] Qin L., Chen Q., Cheng H., Chen Q., Li J.-F., Wang Q.-M. // J. Appl. Phys. 2011. Vol. 110. P. 094511-1-094511-11.

[5] Prasad M., Sahula V., Vinod Kumar K.V. // IEEE Trans. on Device Mater. Reliability. 2014. Vol. 14. N 1. P.545-554.

[6] Hickernell F.S. // ТИИЭР. 1976. Т. 64. № 5. С. 70-76.

[7] Nalamwar A.L., Wagers R.S., Epstein M. // J. Appl. Phys. 1977. Vol. 48. N 6. P. 2175-2178.

[8] Веселов А.Г., Елманов В.И., Кирясова О.А., Никулин Ю.В. // ЖТФ. 2017. Т. 87. Вып. 3. С. 448-452.

[9] Krupanidhi S.B., Sayer M. // J. Appl. Phys. 1984. Vol. 56. N 11. P. 3308-3318.

[10] Yan Z., Zhou X.Y., Pang G.K.H., Zhang T., Liu W.L., Cheng J.G., Song Z.T., Feng S.L., Lai L.H., Chen J.Z., Wang Y. // Appl. Phys. Lett. 2007. Vol. 90. P. 143503-1143503-3.

[11] Yanagitani T., Mishima N., Matsukawa M., Watanabe Y. // IEEE. Transactions on Ultrasonics, Ferroelectrics, and Frequency Control. 2007. Vol. 54. N 4. P. 701-704.

[12] Lehmann H.W., Widmer R. // J. Appl. Phys. 1973. Vol. 44. N 9. P. $3868-3879$.

[13] Веселов А.А., Веселов А.Г. // Письма в ЖТФ. 2002. Т. 28. Вып. 13. С. 83-87.

[14] Бурылин Е.И., Веселов А.А., Веселов А.Г., Джумалиев А.С., Иванов С.Н., Кирясова О.А. // Письма в ЖТФ. 2000. Т. 26. Вып. 7. С. 31-34.

[15] Бурылин Е.И., Веселов А.Г., Джуммалиев А.С., Елманов В.И., Истомин С.Н., Кирясова О.А., Пушкарева Т.А., Рябушкин С.Л. // ЖТФ. 2007. Т. 77. Вып. 5. С. 130-132.

[16] Rughoobur G., DeMiguel-Ramos M., Mirea T., Clement M., Olivares J., Díaz-Durán B., Sangrador J., Miele I., Milne W.I., Iborra E., Flewitt A.J. // Appl. Phys. Lett. 2016. Vol. 108. P. 034103-1-034103-5.

[17] Yanagitani T., Kiuch M. // IEEE Ultrasonics Symposium. 2007. P. 1413-1416.

[18] Serhane R., Khales H. // IEEE Joint UFFC, EFTF and PFM Symposium. 2013. P. 275-278.

[19] Hillman G.D., Seguin H.J.J. // J. Appl. Phys. 1973. Vol. 44. N 11. P. 5053-5055.

[20] Kushida K., Takeuchi H. // J. Appl. Phys. 1984. Vol. 56. N 4. P. 1133-1135.

[21] Takayanagi S., Yanagitami T., Matsukawa M., Watanabi Y. // IEEE International Ultrasinic Symposium Proceedings. 2011. P. 2317-2320.

[22] Александров В.А., Веселов А.Г., Кирясова О.А., Сердобинцев А.А. // Письма в ЖТФ. 2012. Т. 38. Вып. 18. С. 41-44.

[23] Tampo H., Fons P., Yamada A., Kim K.-K., Shibata H., Matsubara K., Niki S., Yoshikawa H., Kanie H. // Appl. Phys. Lett. 2005. Vol. 87. P. 141904-1-141904-3. 